\title{
Determination of quorum-sensing signal molecules and virulence factors of Pseudomonas aeruginosa isolates from contact lens-induced microbial keratitis
}

\author{
HUA ZHU, SOPHY J. THURUTHYIL and MARK D. P. WILLCOX \\ Cooperative Research Center for Eye Research and Technology, University of New South Wales, UNSW, \\ Sydney, NSW 2052, Australia
}

\begin{abstract}
The virulence of Pseudomonas aeruginosa in contact lens-induced microbial keratitis has been linked to various extracellular and cell-associated bacterial products, such as proteases and toxins. Recently, a group of bacterial signal molecules, $N$-acyl-homoserine lactones (AHLs), has been reported to play an important role in the regulation of the production of several bacterial virulence factors in $P$. aeruginosa. The aim of this study was to determine the signal molecules produced by $P$. aeruginosa keratitis strains, and to elucidate any possible correlation between the production of signal molecules and the expression of phenotypic characteristics, including protease production, bacterial invasion and acute cytotoxic activity. The presence and profiles of AHLs in ocular $P$. aeruginosa isolates were analysed by a combination of thin-layer chromatography and bioassay. All 17 keratitis isolates produced AHLs. There were differences both in the amounts and the types of AHL production in the various phenotypes of isolates. High levels of AHLs were found among the isolates with high protease activity and invasiveness. Acutely cytotoxic isolates displayed low AHL and protease activities. Invasive strains were more common than cytotoxic strains from keratitis patients. These results suggest that quorum-sensing systems of $P$. aeruginosa display a complexity even within the same species, and the production of certain AHL signal molecules may be associated with certain phenotypes in $P$. aeruginosa.
\end{abstract}

\section{Introduction}

Pseudomonas aeruginosa, one of the most destructive of all the opportunist pathogens, is a major cause of contact lens-related ulcerative keratitis [1,2], which often leads to corneal scarring and vision loss. Virulence of $P$. aeruginosa is multifactorial, involving both secreted and cell-associated bacterial products, such as elastase, alkaline protease, protease IV, exotoxin A and exo-enzyme S [3-6]. Expression of these virulence factors appears to be controlled by signal molecule-dependent cell-cell communication systems, which are used by $P$. aeruginosa to monitor its own population density in a process known as quorum-sensing [7].

Received 6 March 2002; revised version received 28 June 2002; accepted 24 July 2002.

Corresponding author: Dr H. Zhu (e-mail: h.zhu@crcert. unsw.edu.au).
Quorum-sensing signal molecules, $N$-acyl-L-homoserine lactones (AHLs), are fundamental regulatory agents of many processes in $P$. aeruginosa. When present in high enough concentration, these molecules can bind to and activate a transcriptional activator, or $\mathrm{R}$ protein, which in turn induces expression of target genes. Two quorumsensing systems, las and $r h l$, have been reported in $P$. aeruginosa. In the las system, the AHL signal molecule $N$-(3-oxododecanoyl) homoserine lactone (OdDHL) triggers a transcriptional activator, LasR, to induce expression of virulence factors such as elastase and toxin A [8-11]. The signal molecule OdDHL has also been found to be required for microcolony differentiation in Pseudomonas biofilm formation [12]. In the second quorum-sensing system, rhl, the AHL signal $N$ butyryl homoserine lactone (BHL) $[13,14]$ binds and activates the transcriptional protein RhlR to regulate the production of haemolysin and pyocyanin, as well as elastase and alkaline protease $[15,16]$. These systems operate in a hierarchical fashion along with a recently described quinolone signalling system [17]. 
Proteases are important corneal virulence factors. Elastase (mainly LasB elastase) acts alone or together with other $P$. aeruginosa proteases to degrade or inactivate several biologically important substrates, including connective tissues and immune system components [18]. Alkaline protease is able to degrade laminin and other substrates, suggesting a possible role for this enzyme in tissue invasion and dissemination [3]. Recently, protease IV has been characterised as a serine protease and correlated with corneal virulence [4]. It has been demonstrated that a protease IVdeficient strain lacks corneal virulence in both rabbit and mouse models of keratitis [19-21].

P. aeruginosa strains have been classified into three phenotypes: invasive, acute cytotoxic and neither invasive nor cytotoxic [22-24]. Both invasive and cytotoxic types of $P$. aeruginosa are virulent in animal models of corneal infections, and the invasive strains of $P$. aeruginosa cause more severe corneal damage [25]. The invasive or cytotoxic phenotypes are regulated by a type III secretory system and differ in the genes that are under regulatory control of a transcriptional activator, ExsA [26]. However, it is not known how the quorum-sensing systems or particular virulence factors relate to invasiveness and acute cytotoxicity of the organism.

The pathogenic mechanisms of $P$. aeruginosa in contact lens-induced corneal infection and inflammation are not well understood. There are likely to be multiple mechanisms that contribute to the induction of clinical events. A previous study demonstrated that most ocular isolates of $P$. aeruginosa have the ability to produce AHL molecules [27]. In the present study, all the keratitis isolates of $P$. aeruginosa collected at this centre were investigated for their AHL signal molecule profile and their phenotypic characteristics including protease production, invasiveness and acute cytotoxicity. The purpose of the study was to elucidate any possible correlation between AHL production and phenotype of the micro-organisms.

\section{Materials and methods}

\section{Bacterial strains and culture}

Twenty-three $P$. aeruginosa isolates used in the study were isolated from contact lens wearers (Table 1): 17 from contact lens-induced microbial keratitis (MK) patients, 2 from contact lens-induced acute red eye (CLARE) patients and 4 from asymptomatic subjects. Two non-corneal isolates of $P$. aeruginosa, strains PAO1 and ATCC 15442, were also included in the study. The AHL reporter strains Chromobacterium violaceum CV026 and Agrobacterium tumefaciens A136 were kindly supplied by Dr Simon Swift (Institute of Infections and Immunity, University of Nottingham) and Professor Staffan Kjelleberg (School of Microbiology and Immunology, University of New South Wales, Australia), respectively.

Bacteria were grown in Trypticase Soy Broth (Oxoid) at $35^{\circ} \mathrm{C}$ overnight, apart from A. tumefaciens A136 which was cultured on a supplemented minimal A medium [28] at $30^{\circ} \mathrm{C}$. Cells of $P$. aeruginosa were collected and washed once with phosphate-buffered saline (PBS) for invasion and cytotoxicity assays. For examination of the presence of signal molecules and exo-enzyme production, the bacterial culture supernate was collected, filtered through a $0.22-\mu \mathrm{m}$ filter and stored at $-20^{\circ} \mathrm{C}$.

\section{AHL extraction and analytical thin-layer chromatography}

To evaluate the profiles of AHLs produced by the test isolates, bacterial culture supernates were extracted and subjected to analytical thin-layer chromatography (TLC). A 10-ml sample of culture supernate was extracted twice with equal volumes of ethyl acetate and then dried in a fume hood. The residues of extraction were then dissolved in $100 \mu \mathrm{l}$ of HPLC-grade ethyl acetate. Analytical TLC was performed on $\mathrm{C}_{18}$ reversed-phase TLC plates (Whatman, Clifton, NJ, USA). Chromatograms were developed with methanol: water $(60: 40, v: v)$, then air-dried in a fume hood $[29,30]$. The TLC plate was then overlaid with a thin film of agar seeded with the AHL reporter strain $C$. violaceum CV026 that produces the blue colour violacein in response to AHLs with $N$-acyl side chains between 4 and 8 carbons in length (e.g., BHL) [31]. After incubation of the plate at $30^{\circ} \mathrm{C}$ for $24 \mathrm{~h}$, AHLs were located as purple spots on a white background. Alternatively, TLC plates were overlaid with a culture of the reporter bacterium $A$. tumefaciens A136 seeded in a thin layer of agar containing $X$-Gal. This traG::lacZ/traR reporter detects 3-oxo-substituted AHL derivatives with acyl chain length from 4 to 12 carbons (e.g., OdDHL) [29,30]. The development of blue spots indicated the induction of $\beta$-galactosidase expression in the reporter strain caused by the presence of AHLs. All the experiments were performed at least twice.

\section{Bioassay of AHL production}

The level of AHLs in bacterial culture supernates was quantified by examining the ability of samples to activate traR in the $\beta$-galactosidase reporter strain $A$. tumefaciens A136 as described previously [32]. Briefly, an overnight culture of strain A136 in a supplemented minimal A medium [28] was diluted in the same medium to an optical density of 0.2 at $660 \mathrm{~nm}\left(\mathrm{OD}_{660}\right)$ and stored on ice. Each bioassay tube contained $2 \mathrm{ml}$ of the A136 bacterial cell suspension and $0.5 \mathrm{ml}$ of test supernate. The mixtures were incubated at $30^{\circ} \mathrm{C}$ in a water bath for $5 \mathrm{~h}$ with rotation at $100 \mathrm{rpm}$. The $\beta$ galactosidase activity was then measured as described 
Table 1. Characteristics of ocular P. aeruginosa isolates

\begin{tabular}{|c|c|c|c|c|c|c|c|}
\hline \multirow[b]{2}{*}{$\begin{array}{l}\text { Isolate no. } \\
\text { and source }\end{array}$} & \multirow[b]{2}{*}{ Phenotype* } & \multicolumn{2}{|l|}{$\mathrm{AHLs}^{\dagger}$} & \multicolumn{4}{|c|}{ Protease $\left(\mathrm{mU} / \mathrm{ml} / \mathrm{OD}_{660}\right)^{*}$} \\
\hline & & $\begin{array}{c}\text { Type } \\
\text { BHL/HHL/OHHL/OdDHL }\end{array}$ & $\begin{array}{c}\text { Level } \\
\left(\mathrm{U} / \mathrm{ml} / \mathrm{OD}_{660}\right)\end{array}$ & Group & $\begin{array}{l}\text { Total } \\
\text { activity }\end{array}$ & Elastase & $\begin{array}{l}\text { Protease } \\
\text { IV }\end{array}$ \\
\hline \multicolumn{8}{|l|}{ MK } \\
\hline 8 & Invasive & $+/+/+/+$ & $84(5)$ & I & 791 (98) & 673 & 37 (3) \\
\hline 9 & Invasive & $+/+/+/+$ & $127(58)$ & I & 707 (74) & 609 (111) & $15(6)$ \\
\hline 11 & Invasive & $+/+/+/+$ & 79 (24) & I & 635 & 448 (199) & 12 (1) \\
\hline 12 & Invasive & $+/+/+/+$ & $157(54)$ & I & $810(145)$ & $634(30)$ & 24 (1) \\
\hline 13 & Invasive & $+/+/+/+$ & 157 (93) & I & 723 (47) & $665(63)$ & $30(6)$ \\
\hline 14 & Invasive & $+/+/+/+$ & 151 (59) & I & $623(18)$ & $650(76)$ & $17(3)$ \\
\hline 15 & Invasive & $+/+/+/+$ & 137 (16) & I & 909 (4) & 785 (27) & $42(9)$ \\
\hline 16 & Invasive & $+/+/+/+$ & 75 (4) & I & 732 (125) & $656(10)$ & 31 (3) \\
\hline 24 & Invasive & $+/+/+/+$ & $173(62)$ & I & 796 (101) & $628(102)$ & 41 (1) \\
\hline 40 & Invasive & $+/+/+/+$ & $83(30)$ & I & $683(17)$ & $641(38)$ & $27(2)$ \\
\hline 6294 & Invasive & $+/+/+/+$ & $91(26)$ & I & $953(84)$ & 701 (15) & $36(5)$ \\
\hline 32 & ND & $+/+/+/+$ & $146(7)$ & II(a) & $665(106)$ & $625(48)$ & 9 (1) \\
\hline 10 & Cytotoxic & $+/+/+/+$ & $139(40)$ & II(a) & 679 (97) & $638(42)$ & $33(7)$ \\
\hline 23 & Cytotoxic & $+/+/+/+$ & $144(38)$ & II(a) & 794 (95) & 670 & $22(2)$ \\
\hline 26 & Cytotoxic & $-/+/-1+$ & $18(2)$ & II(b) & 553 (16) & 0 & 0 \\
\hline 6206 & Cytotoxic & $-1-1-1+$ & $5(1)$ & II(b) & $106(33)$ & 0 & 0 \\
\hline 17 & Cytotoxic & $-/+/-/+$ & $4(3)$ & III & 244 & 0 & 0 \\
\hline \multicolumn{8}{|l|}{ CLARE } \\
\hline 25 & Invasive & $+/+/+/+$ & 151 & I & 783 (27) & 702 (13) & $32(2)$ \\
\hline 1 & None & $-/+/-/+$ & 13 (3) & III & 139 (39) & 0 & 0 \\
\hline \multicolumn{8}{|l|}{ AS } \\
\hline 5 & Invasive & $+/+/+/+$ & $81(21)$ & I & $640(27)$ & $670(6)$ & $36(1)$ \\
\hline 2 & Cytotoxic & $-1-/-1+$ & $15(6)$ & $\mathrm{II}(\mathrm{b})$ & 161 (13) & 0 & 0 \\
\hline 4 & Cytotoxic & $-1-1-1+$ & $23(9)$ & II(b) & $129(12)$ & 0 & 0 \\
\hline 3 & Cytotoxic & $-1+1-1+$ & $8(5)$ & III & 149 (79) & 0 & 0 \\
\hline \multicolumn{8}{|l|}{ Reference } \\
\hline PAO1 & Invasive & $+/+/+/+$ & 128 & I & $765(56)$ & 674 & $18(2)$ \\
\hline ATCC & None & $+/+/+/+$ & $162(58)$ & I & $536(25)$ & 472 (38) & $18(4)$ \\
\hline 15442 & & & & & & & \\
\hline
\end{tabular}

MK, contact lens-related microbial keratitis; CLARE, contact lens-induced acute red eye; AS, asymptomatic.

* Invasive, $>1000$ cfu invaded $4 \times 10^{5}$ human corneal epithelial cells per well in a 24 -well plate; cytotoxic, $>20 \%$ loss of cell viability; None, neither invasive nor cytotoxic; ND, not determined.

${ }^{\dagger}$ The AHL profiles were examined by thin-layer chromatography and with the reporter strains C. violaceum CV026 and A. tumefaciens A136, respectively. In all tests where OdDHL was produced a spot presumptively identified as ODHL was also seen. The AHL levels, mainly 3-oxosubstituted AHL derivatives, were obtained by evaluating the ability of samples to induce the $\beta$-galactosidase activity in reporter strain $A$. tumefaciens A136, then normalised by dividing the activity (U) with the bacterial culture density at $\mathrm{OD}_{660}$. Mean values (SD) were obtained from three determinations.

The protease profile grouping was based on the zymography results. The activities of total protease, elastase and protease IV were normalised by dividing the enzyme activity $(\mathrm{mU})$ with the bacterial culture density at $\mathrm{OD}_{660}$. Mean values (SD) were obtained from three determinations.

by Miller [28]. The bioassay of AHL production was performed three times for each strain.

\section{Exoprotease assay}

The total protease activities in the culture supernates of the test strains were quantified with Hide azure blue powder (Sigma) as a substrate [33]. LasB elastolytic activity was determined by its ability to cleave elastinCongo red (Sigma) and release red colour, as described by Schad et al. [34]. The protease IV activity of each strain was quantified by its ability to cleave the chromogenic substrate Chromozyme PL (Boehringer Mannheim, Germany), as described by O'Callaghan et al. [4]. For all tests, duplicate tubes were used for each sample and the assays were run three times. All the enzyme activities in the culture supernates were normalised to the densities $\left(\mathrm{OD}_{660}\right)$ of the cultures grown. The protease profile of the culture supernate of each strain was also examined twice by zymography by non-reducing SDS-PAGE in gels containing acrylamide $7.5 \% \mathrm{w} / \mathrm{v}$ and gelatin $0.1 \% \mathrm{w} / \mathrm{v}$ as substrate [35].

\section{In-vitro invasion and cytotoxicity assay}

An immortalised human cornea epithelial cell line (HCE) [36] was used for invasion and acute cytotoxicity assays. HCE cells were cultured to a confluent monolayer in a modified supplemented hormone epithelial medium (SHEM) [37] as described previously [32]. Confluent monolayers of HCE cells were incubated with bacterial suspensions containing $10^{6} \mathrm{cfu} / \mathrm{ml}$ in Eagle's Minimal Essential Medium (MEM; Life technologies, Grand Island, NY, USA) buffered with $\mathrm{NaHCO}_{3} 0.035 \% \mathrm{w} / \mathrm{v}$ and bovine serum albumin $0.6 \% \mathrm{w} / \mathrm{v}$. Bacterial invasion was quantified by a gentamicin survival assay [38] after incubation for $3 \mathrm{~h}$. Briefly, after treatment with MEM containing gentamicin $200 \mathrm{mg} / \mathrm{L}$ for $2 \mathrm{~h}$, the cells were washed once and lysed by treatment with Triton X-100 0.25\% 
$\mathrm{v} / \mathrm{v}$ for $15 \mathrm{~min}$. The surviving bacteria were enumerated by viable counts on nutrient agar. For acute cytotoxicity, culture supernates were collected after incubation of HCE cells with bacteria for $3 \mathrm{~h}$. The percentage of cell death was determined with a cytotoxicity assay kit (Cytox 96; Promega, Madison, WI, USA) that measures the level of lactate dehydrogenase (LDH) released from dead HCE cells. Duplicate wells were used for each isolate, and all tests were performed at least twice.

\section{Statistical analysis}

Production of AHLs and protease between different groups of bacteria was compared by a two-tailed MannWhitney non-parametric test. A two-tailed Pearson $(r)$ correlation test was used to determine the significance of correlation among the properties tested.

\section{Results}

\section{Production of AHL molecules}

There were at least four different AHL spots discovered in most of the test isolates when TLC was used in combination with two AHL biosensors (Table 1). With the reporter strain $C$. violaceum CV026 (Fig. 1), the majority of isolates (17 of 25) of $P$. aeruginosa produced two major AHL spots that most likely represented $\mathrm{BHL}$ and $3-\mathrm{C}_{6}$-homoserine lactone (HHL). Some strains, e.g., isolates 23 and ATCC 15442, showed an additional unidentified spot with mobility between BHL and HHL. There was only a low density of HHL spot detected from isolates 1, 3, 17 and 26. No AHL spots were detected from isolates 2,4 and 6206 with this reporter.

When the reporter strain A. tumefaciens A136 was used, most isolates produced spots corresponding to OdDHL, 3-oxo-C 10 -HL (ODHL), HHL and 3-oxo- $6_{6-}$ HL (OHHL) (Fig. 2 and Table 1) on TLC plates. Isolates 1, 2, 3, 4, 17, 26 and 6206 showed small spots of the OdDHL-like molecule and no other detectable AHLs (Fig. 2 and Table 1). The levels of AHLs in the isolates tested, mainly 3-oxo-substituted AHL derivatives quantified by using the reporter strain $A$. tumefaciens A136, are shown in Table 1. The amounts of AHLs produced by ocular isolates were different. The majority of MK isolates (14 of 17, except isolates 26,6206 and 17) produced high levels of AHLs (>70 $\left.\mathrm{U} / \mathrm{ml} / \mathrm{OD}_{660}\right)$, whereas most of the isolates from asymptomatic subjects ( 3 of 4 ) as well as the CLARE isolate 1 had little AHL activity (Table 1).

\section{Protease production}

The ocular isolates of $P$. aeruginosa produced at least one active protease. The isolates could be classified into three groups based on their protease profiles in gelatin gels. The majority of the isolates belonged to group I with major bands of 51, 98, 120 and 145$163 \mathrm{kDa}$ and a diffuse region of protease activity near the top of the zymogram (Fig. 3). The group II isolates, 10, 23, 32, 2, 4, 26 and 6206 (Fig. 3 and Table 1), with a major band of $98 \mathrm{kDa}$, were divided into subgroups (a) and (b), with or without two minor bands,
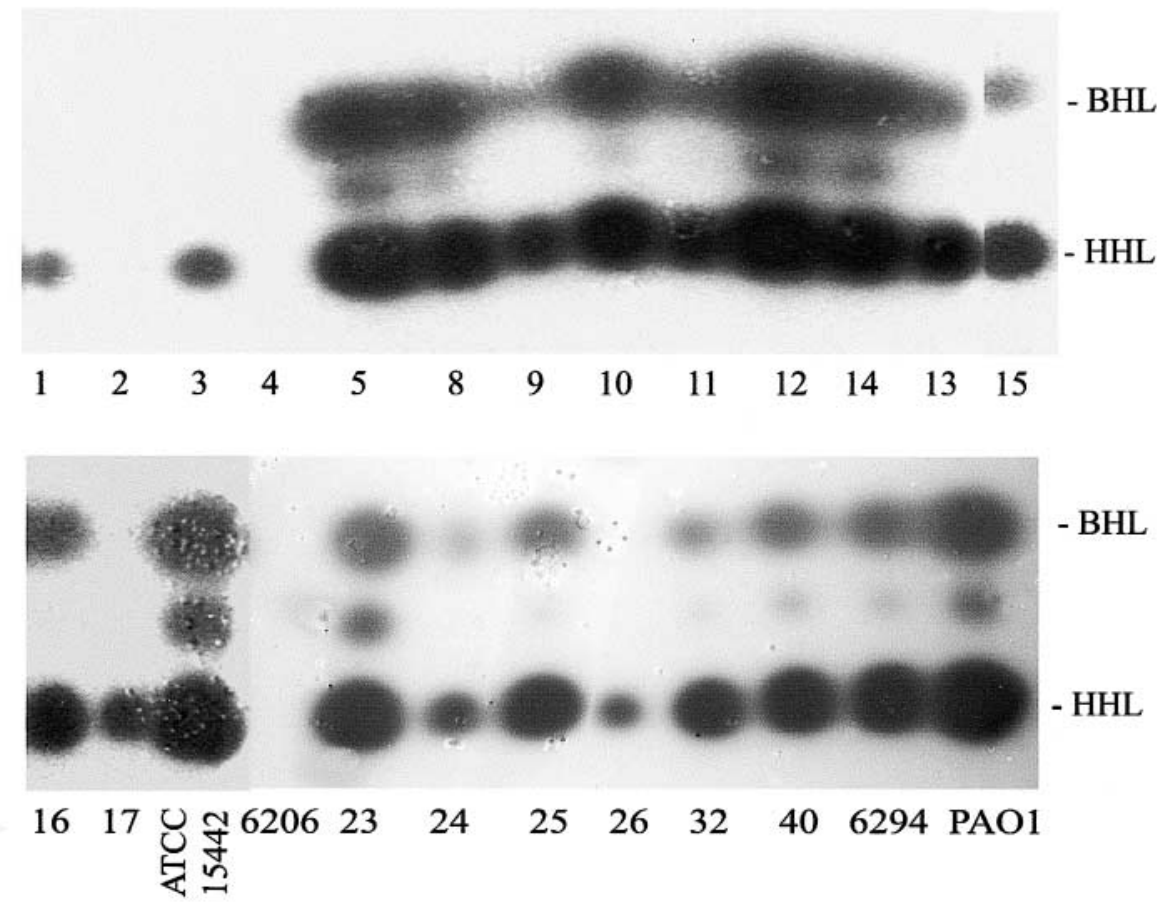

Fig. 1. TLC analyses of AHLs produced by ocular isolates of $P$. aeruginosa. The spots were visualised with biosensor $C$. violaceum CV026. Tentative identification of spots, based on migration of BHL and HHL standards [42], is indicated. 


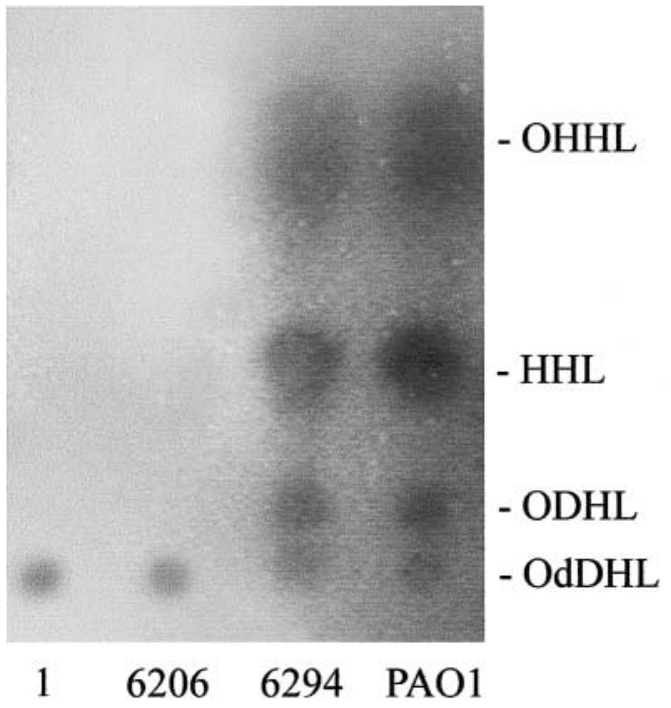

Fig. 2. TLC analyses of AHLs produced by representative strains of ocular isolates of $P$. aeruginosa. The spots were visualised with biosensor $A$. tumefaciens A136. Tentative identification of spots, based on migration of OdDHL, ODHL, HHL and OHHL standards [30, 42], is indicated.

respectively - one of $51 \mathrm{kDa}$ and another $>200 \mathrm{kDa}$ (Fig. 3). The group III isolates included isolates 1, 3 and 17 with one major band of $145 \mathrm{kDa}$ and two minor bands of $51 \mathrm{kDa}$ and $>200 \mathrm{kDa}$.

The total protease, elastase and protease IV activities for each test isolate are listed in Table 1. All isolates of group I and II(a) produced high levels of elastase $\left(>440 \mathrm{mU} / \mathrm{ml} / \mathrm{OD}_{660}\right)$ and high $\left(>20 \mathrm{mU} / \mathrm{ml} / \mathrm{OD}_{660}\right)$ or medium ( $\geqslant 9 \mathrm{mU} / \mathrm{ml} / \mathrm{OD}_{660},<20 \mathrm{mU} / \mathrm{ml} / \mathrm{OD}_{660}$ ) levels of protease IV. Isolates 2, 4, 26, 6206, 1, 3 and 17 , belonging to groups II(b) and III, did not possess detectable elastase and protease IV activities.

\section{Invasion and cytotoxicity of $P$. aeruginosa strains}

Corneal isolates of $P$. aeruginosa showed differences in their abilities to invade or produce acute cytotoxicity in HCE cells (Table 1). All the test strains were either invasive (viable counts $>1000 \mathrm{cfu}$ in the invasion assay) or cytotoxic (culture supernates caused $>20 \%$ loss of cell viability) except isolate 1 (255SD186 cfu invasion, 5SD1\% cytotoxicity) and strain ATCC 15442 (247SD115 cfu invasion, 7 SD 3\% cytotoxicity), which were neither invasive nor cytotoxic. Isolate 32 was gentamicin-resistant (therefore invasion could not be quantified) and not cytotoxic. More MK isolates were invasive than were cytotoxic $(p<0.01)$. Three of four isolates from asymptomatic subjects were cytotoxic but not invasive. Of the two CLARE isolates, one was noncytotoxic and non-invasive and the other was invasive. The invasive isolates had low or no cytotoxicity, and the cytotoxic isolates showed little to no invasiveness, as shown previously [39].

\section{Correlation between the production of AHLs and the phenotypes}

The isolates with high levels of AHLs ( $>70 \mathrm{U} / \mathrm{ml} /$ $\mathrm{OD}_{660}$ ), mainly OdDHL and other 3-oxo-substituted AHL derivatives detected by the reporter strain $A$. tumefaciens A136, showed high levels of protease activity. There was a significant correlation between the levels of AHL signal molecules and the production of total proteases (Pearson $r=0.82, \mathrm{p}=0.0001$ ), elastase (Pearson $r=0.88, \mathrm{p}=0.0001$ ) and protease IV (Pearson $r=0.72, \mathrm{p}=0.0001)$. Moreover, all the isolates that showed high protease activities also exhibited high numbers and intensity of AHL spots on TLC plates (Table 1).

The mean AHL levels (Fig. 4) and total protease activity (Fig. 5) for invasive isolates were significantly higher than for cytotoxic isolates ( $p<0.01$ for both). All invasive isolates had a similar AHL profile and displayed group I protease profiles. Cytotoxic isolates, except group II(a) isolates 10 and 23, possessed lower amounts and numbers of AHLs (with a lack of BHL) and low protease activity (profiles belonging to either group II(b) or group III). The non-invasive and noncytotoxic CLARE isolate 1 showed low levels of AHLs and proteases, but strain ATCC 15442 produced high levels of AHLs and proteases.

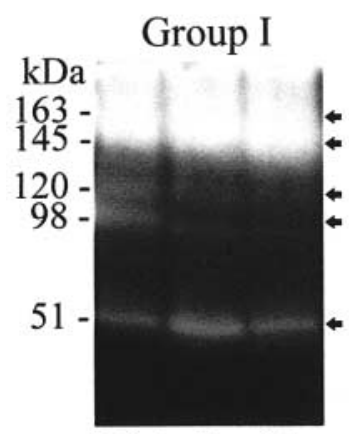

$6294 \quad 8 \quad 15$
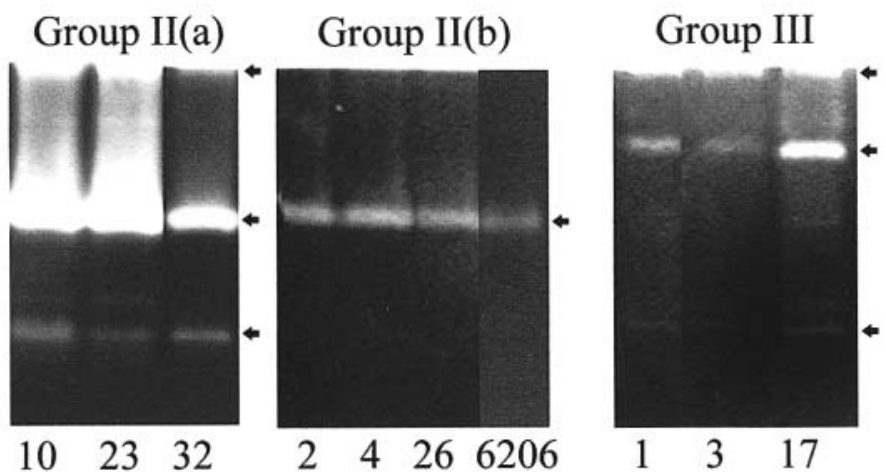

Fig. 3. Gelatin zymograms of proteases produced by representative strains from three different protease groups of ocular isolates of P. aeruginosa. Group I shows major bands of 51, 98, 120 and $145-163 \mathrm{kDa}$, and a diffuse region of protease activity near the top of the zymogram; group II(a) shows a major band at $98 \mathrm{kDa}$ and two minor bands at $>200 \mathrm{kDa}$ and $51 \mathrm{kDa}$; group II(b) shows a band of $98 \mathrm{kDa}$; group III shows one major band at $145 \mathrm{kDa}$ and two minor bands at $>200 \mathrm{kDa}$ and $51 \mathrm{kDa}$ (arrows). 


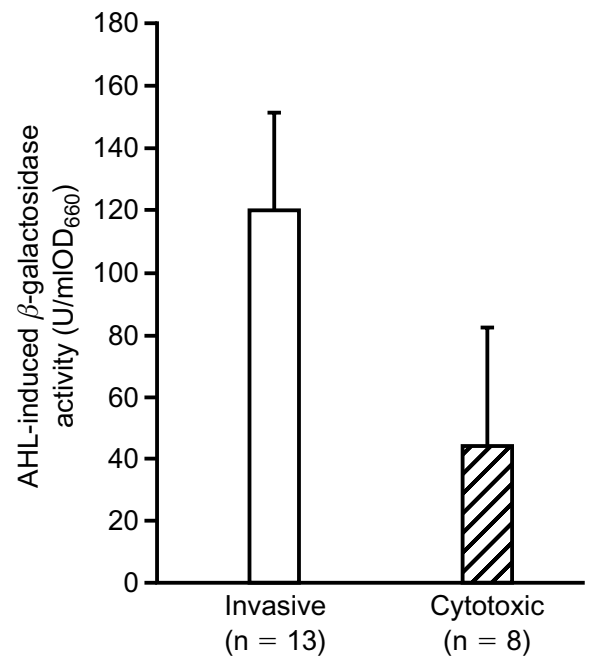

Fig. 4. Comparison of AHL production (as measured in the A. tumefaciens A136 bioassay) in the different phenotypes of $P$. aeruginosa isolates. Values are means and SD. The mean $\beta$ galactosidase activity induced by AHLs in the invasive isolates was significantly higher than in the cytotoxic isolates $(\mathrm{p}<0.01)$.

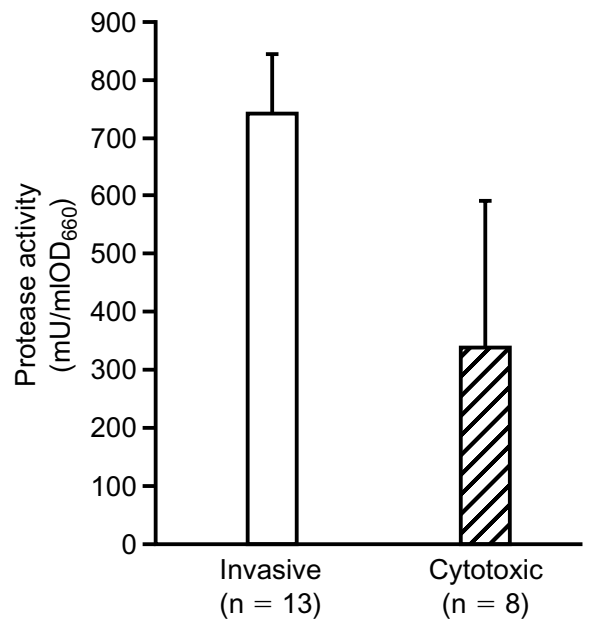

Fig. 5. Comparison of total protease activity in different phenotypes of $P$. aeruginosa isolates. Values are means and SD. The mean protease activity in the invasive isolates was significantly higher than in the cytotoxic isolates $(p<0.01)$.

\section{Discussion}

Examination of the AHL profiles of ocular $P$. aeruginosa isolates revealed that there were differences in the types and levels of AHL production. The AHL profiles of $\mathrm{MK}$ isolates were not identical. Most $P$. aeruginosa isolates produced at least four AHLs and this agrees with previous reports [13,30, 40-42]. $P$. aeruginosa PAO1, a non-ocular strain, has been shown to produce at least four different AHLs - two major AHLs (OdDHL and BHL) and two minor AHLs (OHHL and HHL) [41]. In the current study, seven isolates 17, 26, 6206, 1, 2, 3 and 4) of 23 ocular isolates, including three MK isolates (17, 26 and 6206), produced very low levels of AHLs (mainly OdDHL and HHL), indicating the complexity of the quorumsensing systems even within the same species. It has been reported that environmental conditions determine the AHL production in $P$. aeruginosa as cystic fibrosis clinical isolates produced higher levels of BHL than OdDHL in biofilms but not when grown in broth culture [43]. In a previous study, AHLs were detected when invasive $P$. aeruginosa strains were co-cultured with human corneal epithelial cells, and these mammalian cells stimulated the bacteria to produce more protease activities, due to greater AHL production, than in broth culture [32]. Thus, it has to be borne in mind that the profiles of quorum-sensing signal molecules of $P$. aeruginosa in different environments may be quite different. Further investigation of AHL production in vivo or AHL-controlled gene regulation during corneal infection is warranted.

Signal molecules OdDHL and BHL are involved in regulation of the expression of elastase $[8,10]$. The observation in the present study that high levels of AHLs were always present in isolates with high levels of elastase, and those isolates with little to no detectable AHLs were defective in the production of elastase supports previous findings [8, 10]. Furthermore, the protease IV-deficient isolates in the present study showed little or no detectable OdDHL and BHL, indicating that OdDHL- and BHL-mediated quorumsensing systems may also be involved in the control of the production of protease IV in $P$. aeruginosa. Protease IV is one of the virulence determinants in $P$. aeruginosa during corneal infection. $P$. aeruginosa strains that produce protease IV are highly damaging to rabbit and mouse corneas whereas strains that are deficient in protease IV have reduced virulence $[4,20]$. The regulation of protease IV production is not well known and warrants further investigation.

$P$. aeruginosa invasive and acutely cytotoxic strains differ in genes that are regulated by ExsA, a transcriptional activator. Invasive $P$. aeruginosa strains possess the genes exoS and exoT but lack exoU [44], whereas acutely cytotoxic $P$. aeruginosa strains possess exoU and exoT but lack exoS [26]. It is not known whether AHL-mediated quorum-sensing systems are directly involved in the regulation of the corresponding exotoxins (ExoS, ExoT and ExoU). P. aeruginosa secretes several other potentially cytotoxic factors, including exotoxin A, haemolysin and the phenazine derivative pyocyanin [45], which are known to be regulated by AHL-mediated quorum-sensing systems $[15,16]$. However, the present study revealed that most of the acutely cytotoxic isolates (6 of 8 strains) produce low levels of AHLs, suggesting that those extracellular virulence factors regulated by AHL-mediated quorumsensing might not be essential to cause acute epithelial cell death. The other two cytotoxic isolates (10 and 23) displayed high AHL and protease activities similar to invasive isolates, indicating the diversity and complexity of the phenotypes of ocular $P$. aeruginosa isolates. 
An earlier study suggested that exoprotease production regulated by AHLs in invasive $P$. aeruginosa strains may contribute to the disruption of human corneal epithelial cells at a late stage after challenge [32]. The findings in the current study that high levels of AHLs and proteases are present in all invasive isolates also suggests that high protease activities may be the mechanism by which the organism induces chronic cell death in mammalian cells rather than acute cytotoxicity. However, in the present study the protease activities and invasiveness of the isolates were correlated only with the AHLs detectable by the reporter strain A. tumefaciens A136. The precise role and relationship between the production of each AHL and the different bacterial phenotypes need to be further elucidated with more specific and sensitive AHL detection methods.

All the MK isolates of $P$. aeruginosa were either invasive or acutely cytotoxic to human corneal epithelial cells, and the ability of any particular isolate to invade or induce cytotoxicity was inversely correlated. These results agree with previous findings with murine corneal epithelial cells [39]. The present study suggests that different phenotypes of $\mathrm{MK}$ isolates not only differ in their ability to invade or induce cytotoxicity in HCE cells, but also differ in their ability to produce various extracellular products such as AHLs and proteases. Invasive isolates produced quantitatively and qualitatively more AHLs and proteases compared with cytotoxic isolates. This may partially explain the previous findings that the invasive strain 6294 caused more severe corneal damage in an animal model compared with a cytotoxic strain 6206 [23]. Corneas infected with an invasive strain of $P$. aeruginosa often lose their epithelial layers in the affected area, leaving an exposed stroma [23]. High levels of proteases produced by invasive strains may account for this phenomenon. The observation that more invasive isolates were isolated from MK events may imply that invasive strains have a higher potential to induce such infection.

In conclusion, virulence determinants in various phenotypes of the MK isolates were different. Isolates either had the ability to produce high levels of AHLs and proteases and to invade corneal epithelial cells or they produced low levels of AHLs and proteases and induced an acute cytotoxic effect in corneal epithelial cells. The results suggest that bacterial signal molecules (AHLs) may be associated with the production of proteases and expression of the invasive phenotype in P. aeruginosa.

This work was supported by the Australian Federal Government through the Cooperative Research Centers programme.

\section{References}

1. Cheng KH, Leung SL, Hoekman HW et al. Incidence of contact-lens-associated microbial keratitis and its related morbidity, Lancet 1999; 354: 181-185.

2. Donshik PC. Contact lenses and microbial keratitis. CLAO J 1997; 23: 148.

3. Twining SS, Kirschner SE, Mahnke LA, Frank DW. Effect of Pseudomonas aeruginosa elastase, alkaline protease, and exotoxin A on corneal proteinases and proteins. Invest Ophthalmol Vis Sci 1993; 34: 2699-2712.

4. O'Callaghan RJ, Engel LS, Hobden JA, Callegan MC, Green LC, Hill JM. Pseudomonas keratitis. The role of an uncharacterized exoprotein, protease IV, in corneal virulence. Invest Ophthalmol Vis Sci 1996; 37: 534-543.

5. Iglewski BH, Burns RP, Gipson IK. Pathogenesis of corneal damage from Pseudomonas exotoxin A. Invest Ophthalmol Vis Sci 1977; 16: 73-76.

6. Krall R, Sun J, Pederson KJ, Barbieri JT. In vivo Rho GTPaseactivating protein activity of Pseudomonas aeruginosa cytotoxin ExoS. Infect Immun 2002; 70: 360-367.

7. Fuqua C, Winans SC, Greenberg EP. Census and consensus in bacterial ecosystems: the LuxR-LuxI family of quorum-sensing transcriptional regulators. Annu Rev Microbiol 1996; 50: $727-751$.

8. Passador L, Cook JM, Gambello MJ, Rust L, Iglewski BH. Expression of Pseudomonas aeruginosa virulence genes requires cell-to-cell communication. Science 1993; 260: 1127-1130.

9. Gambello MJ, Iglewski BH. Cloning and characterization of the Pseudomonas aeruginosa lasR gene, a transcriptional activator of elastase expression. $J$ Bacteriol 1991; 173: 3000-3009.

10. Toder DS, Gambello MJ, Iglewski BH. Pseudomonas aeruginosa LasA: a second elastase under the transcriptional control of lasR. Mol Microbiol 1991; 5: 2003-2010.

11. Gambello MJ, Kaye S, Iglewski BH. LasR of Pseudomonas aeruginosa is a transcriptional activator of the alkaline protease gene (apr) and an enhancer of exotoxin A expression. Infect Immun 1993; 61: 1180-1184.

12. Davies DG, Parsek MR, Pearson JP, Iglewski BH, Costerton JW, Greenberg EP. The involvement of cell-to-cell signals in the development of a bacterial biofilm. Science 1998; 280: 295-298.

13. Pearson JP, Passador L, Iglewski BH, Greenberg EP. A second $\mathrm{N}$-acylhomoserine lactone signal produced by Pseudomonas aeruginosa. Proc Natl Acad Sci USA 1995; 92: 1490-1494.

14. Pearson JP, Van Delden C, Iglewski BH. Active efflux and diffusion are involved in transport of Pseudomonas aeruginosa cell-to-cell signals. J Bacteriol 1999; 181: 1203-1210.

15. Brint JM, Ohman DE. Synthesis of multiple exoproducts in Pseudomonas aeruginosa is under the control of RhlR-RhlI, another set of regulators in strain PAO1 with homology to the autoinducer-responsive LuxR-LuxI family. J Bacteriol 1995; 177: 7155-7163.

16. Latifi A, Winson MK, Foglino $\mathrm{M}$ et al. Multiple homologues of LuxR and LuxI control expression of virulence determinants and secondary metabolites through quorum sensing in Pseudomonas aeruginosa PAO1. Mol Microbiol 1995; 17: 333-343.

17. Pesci EC, Milbank JBJ, Pearson JP et al. Quinolone signaling in the cell-to-cell communication system of Pseudomonas aeruginosa. Proc Natl Acad Sci USA 1999; 96: 11229-11234.

18. Morihara K, Homma JY. Pseudomonas proteases. In: Holder JA (ed) Bacterial enzymes and virulence. Boca Raton, FL, CRC Press. 1985.

19. Engel LS, Hobden JA, Moreau JM, Callegan MC, Hill JM, O'Callaghan RJ. Pseudomonas deficient in protease IV has significantly reduced corneal virulence. Invest Ophthalmol Vis Sci 1997; 38: 1535-1542.

20. Engel LS, Hill JM, Moreau JM, Green LC, Hobden JA, O'Callaghan RJ. Pseudomonas aeruginosa protease IV produces corneal damage and contributes to bacterial virulence. Invest Ophthalmol Vis Sci 1998; 39: 662-665.

21. Engel LS, Hill JM, Caballero AR, Green LC, O'Callaghan RJ. Protease IV, a unique extracellular protease and virulence factor from Pseudomonas aeruginosa. J Biol Chem 1998; 273: $16792-16797$

22. Fleiszig SM, Lee EJ, Wu C et al. Cytotoxic strains of Pseudomonas aeruginosa can damage the intact corneal surface in vitro. CLAO J 1998; 24: 41-47.

23. Cole N, Willcox MD, Fleiszig SM et al. Different strains of Pseudomonas aeruginosa isolated from ocular infections or inflammation display distinct corneal pathologies in an animal 
model. Curr Eye Res 1998; 17: 730-735.

24. Cowell BA, Willcox MD, Hobden JA, Schneider RP, Tout S, Hazlett LD. An ocular strain of Pseudomonas aeruginosa is inflammatory but not virulent in the scarified mouse model. Exp Eye Res 1998; 67: 347-356.

25. Cole N, Bao S, Thakur A, Willcox M, Husband AJ. KC production in the cornea in response to Pseudomonas aeruginosa challenge. Immunol Cell Biol 2000; 78: 1-4.

26. Fleiszig SM, Wiener-Kronish JP, Miyazaki H et al. Pseudomonas aeruginosa-mediated cytotoxicity and invasion correlate with distinct genotypes at the loci encoding exoenzyme $\mathrm{S}$. Infect Immun 1997; 65: 579-586.

27. Zhu H, Thuruthyil SJ, Willcox MDP. Production of $N$-acyl homoserine lactones by Gram-negative bacteria isolated from contact lens wearers. Clin Exp Ophthalmol 2001; 29: 150-152.

28. Miller J (ed). Experiments in molecular genetics. Cold Spring Harbor, NY, Cold Spring Harbor Laboratory Press. 1976.

29. Fuqua C, Winans S. Conserved cis-acting promoter elements are required for density-dependent transcription of Agrobacterium tumefaciens conjugal transfer genes. J Bacteriol 1996; 178: $435-440$.

30. Shaw PD, Ping G, Daly SL et al. Detecting and characterizing $\mathrm{N}$-acyl-homoserine lactone signal molecules by thin-layer chromatography. Proc Natl Acad Sci USA 1997; 94: 60366041 .

31. McClean KH, Winson MK, Fish L et al. Quorum sensing and Chromobacterium violaceum: exploitation of violacein production and inhibition for the detection of $\mathrm{N}$-acylhomoserine lactones. Microbiology 1997; 143: 3703-3711.

32. Zhu H, Thuruthyil SJ, Willcox MDP. Invasive strains of Pseudomonas aeruginosa are able to cause epithelial cell cytotoxicity that is dependent on bacterial cell density. Clin Exp Ophthalmol 2000; 28: 201-204.

33. Howe TR, Iglewski BH. Isolation and characterization of alkaline protease-deficient mutants of Pseudomonas aeruginosa in vitro and in a mouse eye model. Infect Immun 1984; 43: 1058-1063.

34. Schad PA, Bever RA, Nicas TI, Leduc F, Hanne LF, Iglewski $\mathrm{BH}$. Cloning and characterization of elastase genes from Pseudomonas aeruginosa. J Bacteriol 1987; 169: 2691-2696.

35. Heussen C, Dowdle ED. Electrophoretic analysis of plasminogen activators in polyacrylamide gels containing sodium dodecyl sulfate and copolymerized substrates. Anal Biochem 1980; 102: 196-202.

36. Araki-Sasaki K, Ohashi Y, Sasabe $\mathrm{T}$ et al. An SV40immortalized human corneal epithelial cell line and its characterization. Invest Ophthalmol Vis Sci 1995; 36: 614-621.

37. Jumblatt MM, Neufeld AH. Beta-adrenergic and serotonergic responsiveness of rabbit corneal epithelial cells in culture. Invest Ophthalmol Vis Sci 1983; 24: 1139-1143.

38. Fleiszig SM, Zaidi TS, Fletcher EL, Preston MJ, Pier GB. Pseudomonas aeruginosa invades corneal epithelial cells during experimental infection. Infect Immun 1994; 62: 34853493.

39. Fleiszig SM, Zaidi TS, Preston MJ, Grout M, Evans DJ, Pier GB. Relationship between cytotoxicity and corneal epithelial cell invasion by clinical isolates of Pseudomonas aeruginosa. Infect Immun 1996; 64: 2288-2294.

40. Pearson JP, Gray KM, Passador L et al. Structure of the autoinducer required for expression of Pseudomonas aeruginosa virulence genes. Proc Natl Acad Sci USA 1994; 91: 197-201.

41. Winson MK, Camara M, Latifi A et al. Multiple $N$-acyl-Lhomoserine lactone signal molecules regulate production of virulence determinants and secondary metabolites in Pseudomonas aeruginosa. Proc Natl Acad Sci USA 1995; 92: 94279431.

42. Geisenberger O, Givskov M, Riedel K, Hoiby N, Tummler B, Eberl L. Production of $N$-acyl-L-homoserine lactones by Pseudomonas aeruginosa isolates from chronic lung infections associated with cystic fibrosis. FEMS Microbiol Lett 2000; 184: 273-278.

43. Singh PK, Schaefer AL, Parsek MR, Moninger TO, Welsh MJ, Greenberg EP. Quorum-sensing signals indicate that cystic fibrosis lungs are infected with bacterial biofilms. Nature 2000; 407: $762-764$.

44. Finck-Barbancon V, Goranson J, Zhu L et al. ExoU expression by Pseudomonas aeruginosa correlates with acute cytotoxicity and epithelial injury. Mol Microbiol 1997; 25: 547-57.

45. Wilson R, Sykes DA, Watson D, Rutman A, Taylor GW, Cole PJ. Measurement of Pseudomonas aeruginosa phenazine pigments in sputum and assessment of their contribution to sputum sol toxicity for respiratory epithelium. Infect Immun 1988; 56: 2515-2517. 